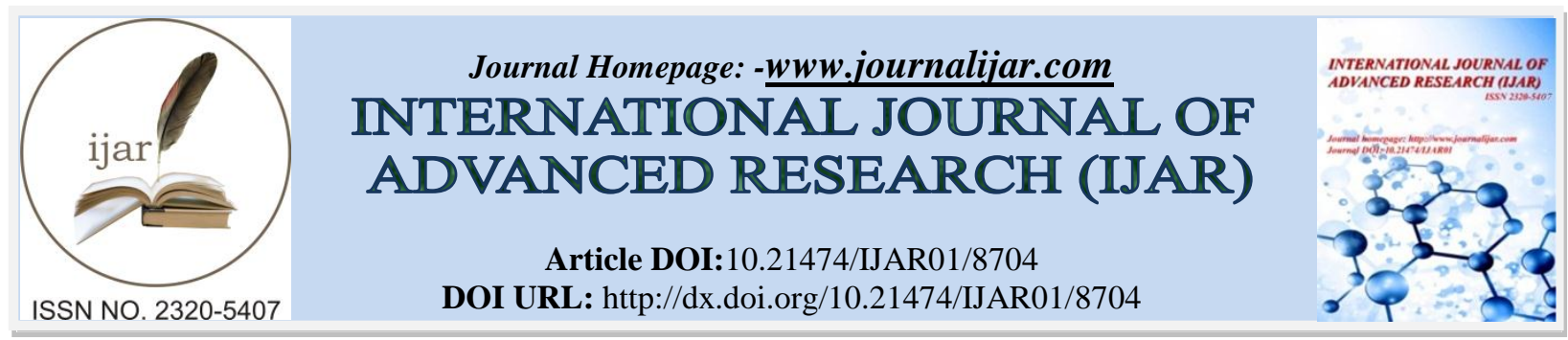

RESEARCH ARTICLE

\title{
INFLUENCE OF EDUCATIONAL PROGRAM ON SOCIAL MATURITY AMONG CHILDREN RESIDING IN ORPHANAGES.
}

\section{Sairabanu Daragad ${ }^{1}$ and Dr. K. S. Roopa ${ }^{2}$.}

1. Ph.D Research Scholar, Department of Human Development and Research Centre, Smt. VHD. Central Institute of Home Science (Autonomous), Seshadri Road, Bangalore 560 001, Karnataka, India.

2. Guide, Associate Professor and HOD, Department of Human Development and Research Centre, Smt. VHD. Central Institute of Home Science (Autonomous), Seshadri Road, Bangalore 560 001, Karnataka, India.

\section{Manuscript Info}

..........................

Manuscript History

Received: 15 January 2019

Final Accepted: 17 February 2019

Published: March 2019

Key words:-

Social Maturity, Dimensions,

Orphanage, Children.

\section{Abstract}

The main aim of the project was to study the influence of educational program on social maturity among boys and girls residing in orphanages at Urban Bangalore district. Self structured questionnaire was developed and administered on a sample of 80 children which consisted of 40 boys and 40 girls, between the age group of 9-12 years. A module of intervention program was developed by the researcher and executed for the experimental group of respondents for a period of 3 months separately for boys and girls in the selected orphanages. The statistical analysis was carried out by applying percentage, standard deviation, mean, chi square and paired ' $t$ ' test. The findings revealed that, majority of boys and girls belonged to the age group of 12 years and were from non-orphans category (presence of both the parents but living in orphanages). Further, the results showed in post-test the mean score percentage found to be higher as compared to pre-test mean score which is significant at 5\% level which showed the influence of educational program. In all the dimensions of social maturity the ' $t$ ' values found to be statistically significant among $(\mathrm{p}<0.05)$ both boys and girls. During the post-test both boys and girls showed a higher score on the level of social maturity as compared to pre-test scores, the obtained chi-square value (93.49) found to be significant beyond 5 percent level.

\section{Introduction:-}

Childhood is a crucial stage of life in terms of a child's physical, intellectual, emotional and social development. A child who is below 18 years of age and who has lost one or both parents may be defined as an orphan (George, 2011). Maternal orphan is referred to a child who has lost their mother and paternal orphan is referred to a child who has lost their father. Social orphans are children who are living without parents because of abandonment or because their parents gave them up as a result of poverty, alcoholism or imprisonment, etc., (Dillon, 2008).

An orphanage is a residential institution devoted to the care of orphans - children whose biological parents are deceased / otherwise unable / unwilling to care for them. Biological parents or grandparents are legally responsible 
for supporting children, but in the absence of these or relatives willing to take care of the children, they become a ward of the state and due to these circumstances established orphanages are providing care, housing and education for the children.

Children living in orphanages for prolonged periods may be behind in development goals, and may have problems in mental health. It may include difficulty with emotions (expressing them, identifying them, regulating them), being easily overwhelmed, hyper-vigilance, overwhelming anxiety, disassociation, volatility (easily set-off, rages), impaired cognition and reasoning skills, depression, sense of hopelessness. As children are the future of the country we should help them to acquire the good qualities for their successful living.

Social maturity is an essential aspect of human life and it is characterized by the individual's ability to establish social relations independently with different social groups of the society. Socially mature children have confidence to face reality for their integrity and are well developed in discriminating power to make appropriate decisions about their personal and social life. It also includes such behavioral forms as group compatibility, kindness and sympathy, fair play, emotional adjustability, courtesy and politeness, dependability, self-confidence, co-operation, leadership and cheerfulness.

\section{Dimensions of Social Maturity:}

1. Adaptation / Socialization: Socialization is the process through which people are taught to be proficient members of a society. It describes the ways that people come to understand societal norms and expectations, to accept society's beliefs and to be aware of societal values.

2. Self Direction: It describes a process by which individuals take the initiative, with or without the assistance of others, in diagnosing their learning needs, formulating learning goals, identify human and material resources for learning, choosing and implement appropriate learning.

3. Human Relation: It addresses interpersonal behaviors. Factors that are considered include leadership; communication; team building; and negotiation, facilitation and mediation abilities.

4. Occupation \& Productivity/ Communication: Occupation refers to the activities and tasks of daily life that have value and meaning to a person. It includes self-care (i.e. personal care, mobility), leisure (i.e. social activities, sports) and productivity (play, school, employment, homemaking) and communication is the imparting or exchanging of information by speaking, writing, or using some other medium.

5. Civic awareness / Social Values and Ethical Character: It refers to the foundation that makes people active participants in the fabric of their community and beyond. Social values form an important part of the culture of the society. Values account for the stability of social order.

6. Cooperation: The action or process of working together to the same end. Voluntarily arrangement in which two or more entities engage in a mutually beneficial exchange instead of competing.

7. Worthy group membership (Initiative \& Leadership): Belonging, either individually or collectively, to a group. Some memberships may require a fee to join or participate while some do not. Special privileges or benefits are entitled to members although not all members may have the same rights and privileges.

8. Self Care: Is any necessary human regulatory function which is under individual control, deliberate and selfinitiated.

9. Self Realization: It is a scientific process which reveals a new vision and understanding of freedom from worries and fear, scientific solutions to inner and external conflicts, smoother relationships, inner peace, equanimity amid any circumstances, eternal happiness, and experience of true eternal self and experience the depths of spirituality while fulfilling worldly responsibilities.

Socially, children gain a greater appreciation for the complex web of social relationships they inhabit. In contrast to earlier periods of their development characterized by more superficial friendship selections, they become interested in developing fewer, deeper, more selective friendships based on trust and intimacy. They develop more individualized relationships with family members. Their expanded social knowledge drives them towards increasingly sophisticated appreciations of what it means to be a moral person. Starting from a position of relative self-centeredness, children begin to make decisions about right and wrong, considering how they treat other people may influence how other people choose to treat them.

Social maturity is not built into the structure and functioning of the living organism once for all but is molded by the child's experiences and interactions with other persons and their effective one. It is highly culture embedded and ensures the child's happy living in the society. Learning to speak properly during childhood is important because 
speech is an essential tool in socialization. The children who can communicate with their peers with intelligible words, makes better social contacts and is more readily accepted as a member of group. Hence, effective communication is an essential aspect of social maturation.

In the light of the above discussion an attempt was made to assess the level of social maturity of children and to develop a module of educational program to enhance the social maturity and executed for the children residing in orphanages.

\section{Methodology:-}

Objectives:

1. To study the social maturity with respect to nine dimensions viz. socialization, self direction, human relation, communication, civic awareness, cooperation, worthy group membership, self care and self realization among children living in orphanages.

2. To develop a module of intervention program to enhance the social maturity of children.

3. To study the influence of intervention program;

a) On the mean score of children on social maturity.

b) Among boys in the nine dimensions of social maturity.

c) Among girls in the nine dimensions of social maturity.

d) Among children in the nine dimensions of social maturity.

e) On the level of social maturity among boys and girls.

\section{Hypothesis:}

1. There is a significant difference in social maturity with respect to nine dimensions viz. socialization, self direction, human relation, communication, civic awareness, cooperation, worthy group membership, self care and self realization among children living in orphanages.

2. The developed module of intervention program will have a significant influence on the level of social maturity of children.

3. There exist an influence of intervention program;

a) On the mean score of children on social maturity.

b) Among boys in the nine dimensions of social maturity.

c) Among girls in the nine dimensions of social maturity.

d) Among children in the nine dimensions of social maturity.

e) On the level of social maturity among boys and girls.

\section{Selection of sample and sampling technique:}

1. Purposive random sampling technique was adopted. The sample were drawn from the two orphanages catering to boys and girls separately at Urban Bangalore District.

2. A total number of 80 children between the age group of 9-12 years of which 40 were boys and 40 were girls residing in orphanages were selected for the experimental group.

Tool:

A questionnaire was developed by the investigator for the purpose to know the demographic details and to assess the social maturity with respect to nine dimensions; socialization, self direction, human relation, communication, civic awareness, cooperation, worthy group membership, self care and self realization among children which consisted of 66 statements including positive and negative items with 4 point rating scale.

\section{Procedure:}

Two Orphanages catering to boys and girls separately at Urban Bangalore district was identified, the aim and purpose of the study was explained to the administrators. An official permission was obtained by the administrators of the orphanages to conduct the study. The developed questionnaire was administered to the 80 experimental groups of respondents to study the level of social maturity among children. An attempt was made to develop a module of intervention program to enhance the social maturity among children.

The researcher conducted an intervention program separately for boys and girls for a period of 3 months, twice a week and each session consisted of two hours focusing on various life skills i.e. inter personal relationships, problem 
solving, trust and support, creative thinking etc to improve their social maturity. Whether an intervention had any effect on the level of social maturity on the children was evaluated with a retest. After the program leaving a gap of one month the same tool was administered to the children. The dully filled questionnaire was collected and subjected to statistical analysis to study the impact of the program.

\section{Results and Discussion:-}

The data was tabulated and statistically analyzed by applying percentage, Chi square, Mean, Standard Deviation and 'Paired ' $t$ ' test. Figure 1:-shows the classification of respondents by age group.

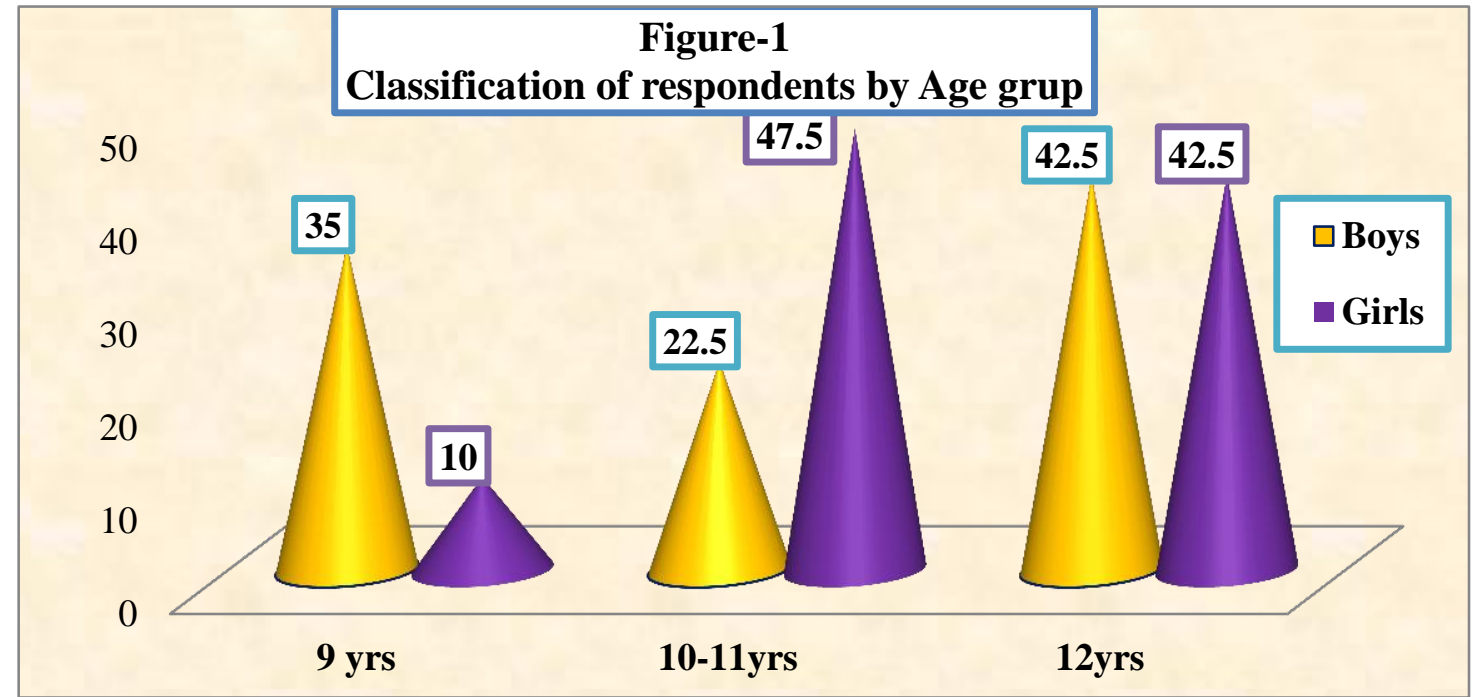

Figure-1 indicates the classification of respondents based on age group. Majority of boys $(42.50 \%)$ were in the age group of 12 years, followed by 35.0 percent were between the age group of 9 years and 22.50 percent of them were from between the age group of 10-11 years. A higher percentage of girls (47.50\%) belonged to 10-11 years of age group whereas 42.50 percent of them were from 12 years of age group and only 10 percent of them were from 9 years of age group.

Figure-2 indicates the classification of respondents by type of orphan. In the study children living in orphanages have been classified into 4 categories. Maternal orphan is referred to a child who has lost their mother and paternal orphan is referred to a child who has lost their father, social orphans are children who are living without parents because of abandonment or because their parents gave them up as a result of poverty, alcoholism or imprisonment, etc., non - orphans are referred to a child who is having both the parents but due to poverty parents have left their children in the orphanages.

A higher percentage of boys (40\%) belonged to non-orphan category followed by 37.50 percent of them were paternal orphans, 12.50 percent of them belonged to social orphan category and only 10 percent of them were maternal orphans. With regard to girls, 92.50 percent of them were non-orphans, 5 percent of them belong to maternal orphan category, 2.50 percent of them were paternal orphans and none of them belonged to social orphan category.

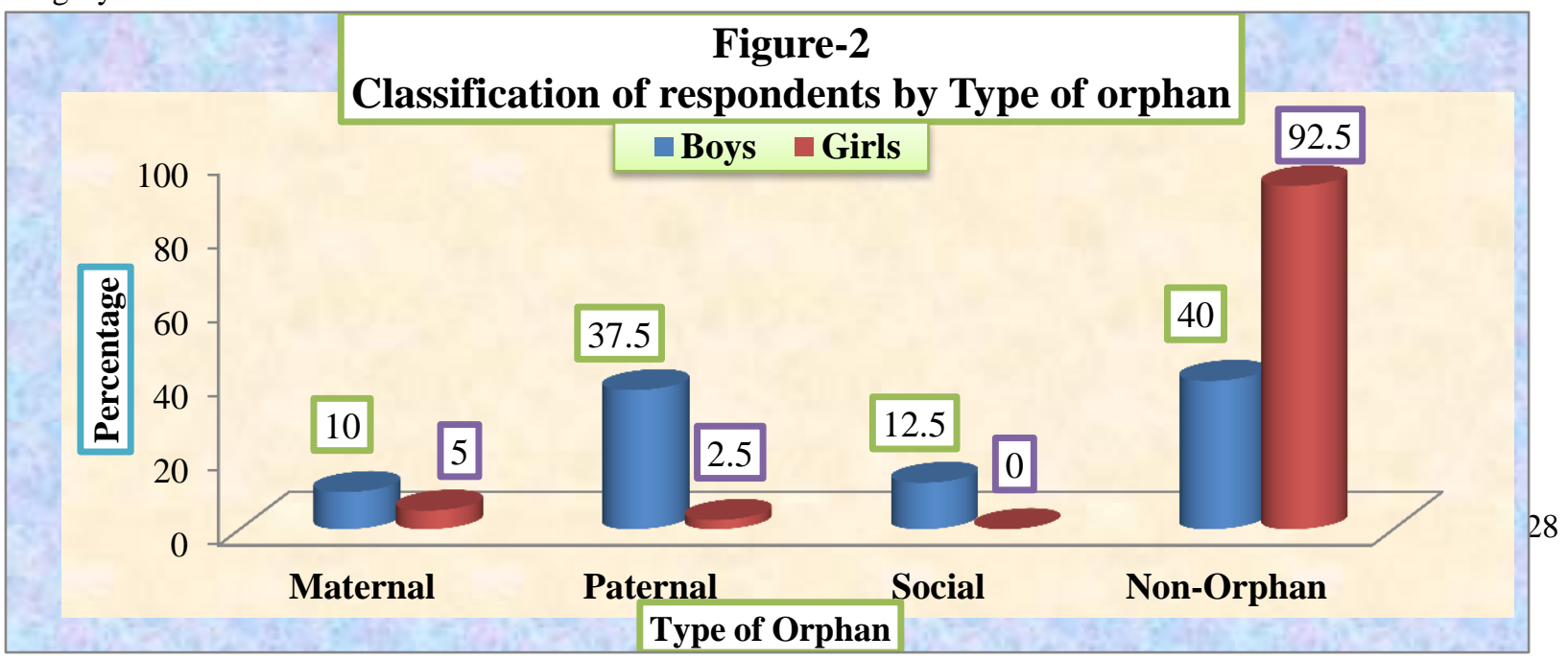


Table - 1 shows the pre and post test scores of boys and girls on overall perception of social maturity. It was hypothesized that there exist an influence of intervention program on the mean score of respondents on social maturity.

Table 1:-Over all Pre test and Post test Mean Scores of Respondents on Social Maturity

\begin{tabular}{|c|c|c|c|c|c|c|c|}
\hline \multirow{3}{*}{ Gender } & \multirow{3}{*}{$\begin{array}{c}\text { Sample } \\
\text { (n) }\end{array}$} & \multirow{3}{*}{ Aspects } & \multirow{2}{*}{\multicolumn{4}{|c|}{ Social Maturity Scores }} & \multirow{3}{*}{$\begin{aligned} \mathrm{N}=80 \\
\text { Paired ' } t \text { ' }^{\text {Test }}\end{aligned}$} \\
\hline & & & & & & & \\
\hline & & & Mean & SD & Mean (\%) & SD (\%) & \\
\hline \multirow{3}{*}{ Boys } & \multirow{3}{*}{40} & Pre-test & 102.75 & 21.20 & 51.90 & 10.70 & \multirow{3}{*}{$13.22 *$} \\
\hline & & Post-test & 152.78 & 7.10 & 77.20 & 3.60 & \\
\hline & & Enhancement & 50.03 & 23.90 & 25.30 & 12.10 & \\
\hline \multirow{3}{*}{ Girls } & \multirow{3}{*}{40} & Pre-test & 114.65 & 12.10 & 57.90 & 6.10 & \multirow{3}{*}{$19.32 *$} \\
\hline & & Post-test & 158.90 & 6.90 & 80.30 & 3.50 & \\
\hline & & Enhancement & 44.25 & 14.40 & 22.30 & 7.30 & \\
\hline \multirow{3}{*}{ Combined } & \multirow{3}{*}{80} & Pre-test & 108.70 & 17.90 & 54.90 & 9.10 & \multirow{3}{*}{ 21.50* } \\
\hline & & Post-test & 155.84 & 7.60 & 78.70 & 3.90 & \\
\hline & & Enhancement & 47.14 & 19.60 & 23.80 & 9.90 & \\
\hline
\end{tabular}

* Significant at $5 \%$ level, $\quad t(0.05,39 d f)=1.96$,

Maximum Score $=198$

Above results showed that, among boys, the mean score percentage found to be higher in post-test (77.20\%) as compared to pre-test mean score percentage (51.90). The mean value of enhancement was 25.30 for boys. The obtained ' $\mathrm{t}$ ' value was found to be significant beyond 5 percent level $\left(\mathrm{t}=13.22^{*}, \mathrm{p}<0.05\right)$ suggesting a significant improvement in score after an intervention. As indicated by the standard deviation, the individual difference in the group has also been reduced during the post test.

The mean score of girls during pre-test was 57.90 and during post-test it was 80.30 . The enhancement in mean score was 22.30. The ' $t$ ' value was found to be 19.32 and was significant beyond 5 percent level suggesting a significant improvement in score after intervention. As indicated by the standard deviation, the individual difference in the group has also been reduced during the post test. Although the post test score is higher for girls, the increase in score after intervention is more for boys. This variation may be due to the variation in the initial scores of the two groups.

Combined results showed the mean score percentage in post-test to be 78.70 as compared to pre-test mean score of 54.90. As indicated by the standard deviation, the individual difference in the group has also been reduced during the post test. The raise is 23.80 and the ' $t$ ' value is found to be 21.50 which is significant at 5 percent level. The results showed the impact of educational program on the overall score of social maturity among both boys and girls by accepting the hypothesis set for the study.

The scores on different dimensions of social maturity classified for the study with regard to pre and post test for boys and girls are given in table 2 and 3.

Table 2:-Dimension wise Mean Pre-test and Post-test scores on Social Maturity among Boys

\begin{tabular}{|c|c|c|c|c|c|c|c|}
\hline \multirow{4}{*}{ Dimensions } & \multirow{2}{*}{\multicolumn{6}{|c|}{ Respondents (\%) }} & \multirow{4}{*}{$\begin{array}{c}\text { Paired } \\
\text { 't' } \\
\text { Test }\end{array}$} \\
\hline & & & & & & & \\
\hline & \multicolumn{2}{|c|}{ Pre-test } & \multicolumn{2}{|c|}{ Post-test } & \multicolumn{2}{|c|}{ Enhancement } & \\
\hline & Mean & SD & Mean & SD & Mean & SD & \\
\hline Socialization & 56.7 & 15.1 & 85.4 & 6.6 & 28.8 & 17.6 & $10.35^{*}$ \\
\hline Self Direction & 62.0 & 18.2 & 83.2 & 10.0 & 21.2 & 22.4 & $5.99 *$ \\
\hline Human Relation & 56.7 & 15.5 & 82.6 & 7.8 & 25.9 & 15.5 & $10.57 *$ \\
\hline Communication & 55.7 & 18.1 & 82.2 & 7.9 & 26.5 & 20.7 & $8.10 *$ \\
\hline Civic awareness & 55.7 & 17.1 & 81.4 & 7.2 & 25.6 & 18.8 & $8.61 *$ \\
\hline Cooperation & 55.8 & 18.1 & 84.4 & 7.2 & 28.6 & 20.9 & $8.65^{*}$ \\
\hline Initiative \& Leadership & 60.0 & 16.8 & 81.7 & 8.2 & 21.7 & 20.5 & $6.69 *$ \\
\hline Self Care & 52.5 & 8.8 & 84.9 & 9.6 & 32.4 & 14.5 & $14.13^{*}$ \\
\hline
\end{tabular}




\begin{tabular}{|l|c|c|c|c|c|c|c|}
\hline Self Realization & 55.6 & 18.4 & 84.7 & 9.6 & 29.2 & 19.6 & $9.42 *$ \\
* t (0.05,39df ) $=\mathbf{1 . 9 6}$
\end{tabular}
Significant at 5\% level,

The results obtained for boys has shown in table 2, it was hypothesized that, there exist an influence of intervention program among boys in the nine dimensions of social maturity. It revealed that, there is an increase in scores on all the dimensions of social maturity i.e., socialization, self direction, human relation, communication, civic awareness, cooperation, initiative and leadership, self care and self realization. The mean score percentage was increased in post-test which showed the impact of intervention program by accepting the hypothesis set for the study. The ' $\mathrm{t}$ ' values in all the dimensions showed the statistically significant increase beyond 5 percent level $(\mathrm{p}<0.05)$.

It was hypothesized that, there exist an influence of intervention program among girls in the nine dimensions of social maturity. Table 3 shows the effect of intervention program on different dimensions of social maturity for girls.

Table 3:-Dimension wise Mean Pre-test and Post-test scores on Social Maturity among Girls

\begin{tabular}{|c|c|c|c|c|c|c|c|}
\hline \multirow{3}{*}{ Dimensions } & \multicolumn{6}{|c|}{ Respondents (\%) } & \multirow{3}{*}{$\begin{array}{c}\text { Paired } \\
\text { 't' } \\
\text { Test }\end{array}$} \\
\hline & \multicolumn{2}{|c|}{ Pre-test } & \multicolumn{2}{|c|}{ Post-test } & \multicolumn{2}{|c|}{ Enhancement } & \\
\hline & Mean & SD & Mean & SD & Mean & SD & \\
\hline Socialization & 63.6 & 11.8 & 85.6 & 7.7 & 22.0 & 15.0 & $9.28 *$ \\
\hline Self Direction & 63.7 & 14.1 & 87.5 & 6.9 & 23.8 & 15.7 & $9.59 *$ \\
\hline Human Relation & 63.8 & 11.5 & 89.2 & 6.4 & 25.4 & 14.6 & $11.00 *$ \\
\hline Communication & 60.8 & 13.4 & 83.1 & 8.7 & 22.2 & 16.1 & $8.72 *$ \\
\hline Civic awareness & 61.4 & 10.8 & 85.0 & 5.8 & 23.6 & 13.6 & $10.97 *$ \\
\hline Cooperation & 66.1 & 10.9 & 88.0 & 7.4 & 21.9 & 12.2 & $11.35^{*}$ \\
\hline Initiative \& Leadership & 63.8 & 12.9 & 88.8 & 6.7 & 25.0 & 14.6 & $10.83 *$ \\
\hline Self Care & 55.1 & 8.9 & 86.0 & 6.1 & 30.8 & 10.7 & $18.21 *$ \\
\hline Self Realization & 65.1 & 10.8 & 89.9 & 8.1 & 24.7 & 14.9 & $10.48 *$ \\
\hline
\end{tabular}

* Significant at $5 \%$ level,

t $(0.05,39 d f)=1.96$

In all the dimensions of social maturity, compared to the pre-test the mean score percentage was increased in posttest which showed the influence of an intervention program by accepting the hypothesis. The 't' values in all the dimensions showed statistically significant increase in scores beyond 5 percent level $(\mathrm{p}<0.05)$.

The pre and post test scores of the respondents on the various dimensions of social maturity has been described in Table 4. It was hypothesized that there exist an influence of intervention program among respondents in the nine dimensions of social maturity.

Table 4:-Dimension wise Mean Pre-test and Post-test Scores on Social Maturity level

\begin{tabular}{|c|c|c|c|c|c|c|c|}
\hline \multirow{3}{*}{ Dimensions } & \multicolumn{6}{|c|}{ Respondents (\%) } & \multirow{3}{*}{$\begin{array}{c}\text { Paired } \\
\text { 't' } \\
\text { Test }\end{array}$} \\
\hline & \multicolumn{2}{|c|}{ Pre test } & \multicolumn{2}{|c|}{ Post test } & \multicolumn{2}{|c|}{ Enhancement } & \\
\hline & Mean & SD & Mean & SD & Mean & SD & \\
\hline Socialization & 60.10 & 13.9 & 85.50 & 7.2 & 25.40 & 16.7 & $13.60 *$ \\
\hline Self Direction & 62.80 & 15.9 & 85.30 & 8.8 & 22.50 & 19.0 & $10.59 *$ \\
\hline Human Relation & 60.20 & 14.0 & 85.90 & 7.8 & 25.60 & 14.9 & $15.37 *$ \\
\hline Communication & 58.30 & 16.0 & 82.60 & 8.3 & 24.40 & 18.6 & $11.73 *$ \\
\hline Civic awareness & 58.60 & 14.5 & 83.20 & 6.7 & 24.60 & 16.3 & $13.50 *$ \\
\hline Cooperation & 61.00 & 15.7 & 86.20 & 7.5 & 25.20 & 17.4 & $12.95 *$ \\
\hline Initiative \& Leadership & 61.90 & 14.7 & 85.20 & 8.2 & 23.30 & 17.6 & $11.84 *$ \\
\hline Self Care & 53.80 & 8.9 & 85.40 & 8.0 & 31.60 & 12.7 & $22.26 *$ \\
\hline
\end{tabular}




\begin{tabular}{|l|c|c|c|c|c|c|c|}
\hline Self Realization & 60.30 & 15.3 & 87.30 & 9.2 & 26.90 & 17.0 & $14.15 *$ \\
* $\mathbf{( 0 . 0 5 , 7 9 d f ) ~}=\mathbf{1 . 9 6}$
\end{tabular}
*ignificant at 5\% level,

A cursory glance at the table showed that in all the dimensions of social maturity the ' $\mathrm{t}$ ' test found to be statistically significant beyond $5 \%$ level there by accepting the hypothesis postulated for the study.

In the first dimension of socialization the mean score has increased from 60.10 to 85.50 from pre to post test with an enhancement score of 25.40. The ' $t$ ' test value was 13.60 and significant beyond 5 percent level. In the case of self direction dimension the score has increased from 62.80 to 85.30 from pre to post test. The enhancement was 22.50 . The calculated ' $t$ ' ratio was found to be 10.59 and was significant at 5 percent level. In the dimension of human relation, the score increased from 60.20 to 85.90 from pre to post test. The enhancement was 25.60 . The ' $t$ ' value of 15.37 was found to be significant beyond 5 percent level. In the area of communication the respondents mean score was found to be 82.60 during post test when compared to pre test score of 58.30. The enhancement was 24.40. The obtained ' $t$ ' value of 11.73 was found to be significant beyond 5 percent level. In the civic awareness domain of social maturity, the score has increased from 58.60 to 83.20 from pre to post test. The enhancement was 24.60 . The ' $t$ ' value was found to be 13.50 and was significant at 5 percent level.

In case of cooperation dimension the respondents mean score was found to be 86.20 during post-test when compared to pre-test score of 61.00 . The enhancement was 25.20. The obtained ' $t$ ' value of 12.95 was found to be significant beyond 5 percent level.

In the area of initiative and leadership the respondents mean score was found to be 85.20 during post-test when compared to pre-test score of 61.90. The enhancement was 23.30. The obtained ' $t$ ' value of 11.84 was found to be significant beyond 5 percent level. In the self care domain of social maturity, the score has increased from 85.40 to 53.80 from pre to post-test. The enhancement was 31.60 . The ' $t$ ' value was found to be 22.26 and was significant at 5 percent level. In case of self realization dimension the respondents mean score was found to be 87.30 during posttest when compared to pre-test score of 60.30. The enhancement was 26.90. The obtained ' $t$ ' value of 14.15 was found to be significant beyond 5 percent level.

The results revealed that there is an impact of educational program on the respondents with significant improvement in the mean score with regard to all the dimensions of social maturity classified for the study. The findings of the study are in line with the study conducted by Jacobs (2011) teaching of life orientation for young children towards becoming responsible and living a productive life which enhance the level of social maturity.

Table 5 indicates the classification of respondents on the level of social maturity during pre and post test.

Table 5:-Classification of Respondents on Pre-test and Post-test Social Maturity level

\begin{tabular}{|c|c|c|c|c|c|c|}
\hline \multirow{3}{*}{ Gender } & \multirow{3}{*}{$\begin{array}{c}\text { Social } \\
\text { Maturity }\end{array}$} & \multicolumn{4}{|c|}{ Classification of Respondents } & \multirow{3}{*}{$\begin{array}{c}\chi^{2} \\
\text { Value }\end{array}$} \\
\hline & & \multicolumn{2}{|c|}{ Pre-test } & \multicolumn{2}{|c|}{ Post-test } & \\
\hline & & $\mathbf{N}$ & $\%$ & $\mathbf{N}$ & $\%$ & \\
\hline \multirow{3}{*}{ Boys $(n=40)$} & Low & 16 & 40.0 & 0 & 0.0 & \multirow{3}{*}{ 41.60* } \\
\hline & Moderate & 24 & 60.0 & 16 & 40.0 & \\
\hline & High & 00 & 0.0 & 24 & 60.0 & \\
\hline \multirow{3}{*}{ Girls $(n=40)$} & Low & 04 & 10.0 & 00 & 0.0 & \multirow{3}{*}{$56.56 *$} \\
\hline & Moderate & 36 & 90.0 & 07 & 17.5 & \\
\hline & High & 00 & 0.0 & 33 & 82.5 & \\
\hline \multirow{3}{*}{ Combined $(\mathrm{n}=80)$} & Low & 20 & 25.0 & 00 & 0.0 & \multirow{3}{*}{ 93.49: } \\
\hline & Moderate & 60 & 75.0 & 23 & 28.8 & \\
\hline & High & 00 & 0.0 & 57 & 71.2 & \\
\hline
\end{tabular}

* Significant at $5 \%$ level, $\chi^{2}(0.05,2 \mathrm{df})=5.991$

It was hypothesized that there exist an influence of intervention program on the level of social maturity among boys and girls. The table values showed that, in pre-test majority of boys $(60.00 \%)$ had moderate level of social maturity, 40 percent of them had low level of maturity and none of them had high level. Whereas, in post-test majority of boys $(60.00 \%)$ had high level of social maturity and 40 percent of them had moderate level. There is an association 
between pre-post test scores on different levels of social maturity among boys. The obtained chi-square value of 41.60 was found to be significant at 5 percent level by accepting the hypothesis set for the study.

Among girls, in pre-test a higher percentage of them (90.00\%) had moderate level of social maturity and only 10 percent of them had low level. Whereas, during post-test, 82.50 percent of them had high level of maturity and 17.50 percent of them had moderate level. The chi-square value is found to be 56.56 and is significant beyond 5 percent level by accepting the hypothesis. Combined results showed that compared to pre-test, after the intervention program majority of respondents $(71.20 \%)$ had high level of social maturity and 28.80 percent of them had moderate level. The obtained chi-square value is 93.49 and is significant beyond 5 percent level. The chi-square value suggests significant association between different levels of social maturity and the pre-post test scores for both boys and girls. As compared to boys, more number of girls have moved to the high level after an intervention. The study supports the findings of the DoE (2002) that life orientation prepares and guides learners for life and its possibilities by equipping them with skills, knowledge and attitudes to enable them to make informed decisions.

The school stands a better chance of providing learners with an opportunity to acquire life orientation skills. The school curriculum should therefore be directly relevant to children's lives by embedding life skills in the curriculum, household management, as well as focusing on health care (Richter et al., 2004).

\section{Conclusion:-}

The findings revealed that, majority of boys and girls belonged to the age group of 12 years and were from nonorphans category. Further, the results showed in post-test, the mean score percentage of children found to be higher as compared to pre-test mean score which is significant at 5\% level which showed the influence of educational program. In all the dimensions of social maturity the ' $\mathrm{t}$ ' values found to be statistically significant among $(\mathrm{p}<0.05)$ both boys and girls. During the post-test both boys and girls showed a higher mean score on the level of social maturity as compared to pre-test scores, the obtained chi-square value (93.49) found to be significant beyond 5 percent level.

A child living in an orphanage being with other children should contribute to the development of relationships in the form of joint productive activity by cooperating with each other, achievements, emphasizing the value of relationships, teaching and learning the roles and responsibilities and also by communicating with other children. Caretakers help them to develop their interactive skills which will be useful for the development of social maturity. The findings of the study showed that educational program has a significant influence on the level of social maturity among children. Educational program focusing on life skills helped the children for the creation of sense of responsibility and also helped to remove the negative effect of being in a state of institutional care.

The findings of the study recommends to develop holistic and integrated policies and programs for orphan children by providing social support, protecting children from violence, building up their resilience and community coping mechanisms.

\section{References:-}

1. Department of Education (DoE) 2002. Revised national curriculum statement grades R-9 (schools): Life Orientation. Pretoria: Department of Education. Available at http://www.ibe.unesco.org/curricula/southafrica/sa_al_lf_2002_eng.pdf. Accessed 1 July 2015.

2. Dillon, S.A., (2008). The missing link: a social orphan protocol to the United Nations Convention on the Rights of the Child.

3. George, A., (2011). State of orphans in the earthly paradise. Econ. Polit. Weekly 46(10):19.

4. Irudayasamy, P., (2006). Institute Of Research and Development and Rural Poor.

5. Jacobs A 2011. Life orientation as experienced by learners: A qualitative study in North-West Province. South African Journal of Education, 31(2):212-223. Available at http://sajournalofeducation.co.za/index.php/saje/article/viewFile/481/243. Accessed 2 July 2015.

6. Richter L, Manegold J \& Pather R., (2004). Family and community interventions for children affected by AIDS. Cape Town: Human Sciences Research Council.

7. Sengendo, J., and Nambi, J., (2004). The Psychological Effect of Orphanhood: A Study of Orphans in Rakai District. 
8. Social Work (Post Graduate Diploma)., (2010). A Study on the social maturity of the children under the department of social welfare submitted by group http://www.scribd.com/doc/137288120/A-Study-on-the-SocialMaturity-of-the-Children-under-the-Department-of-Social-Welfare\#scribd.

9. Tatyana, I., Shulga., Daria, D., Savchenko., and Evgeniya, B. Filinkova., (2016). Psychological Characteristics of Adolescents Orphans with Different Experience of Living in a Family. International Journal of Environmental \& Science Education, Vol. 11, No. 17, pp: 10493-10504. 